\title{
FENOMENA LANSIA MENGHAFAL ALQURAN PADA MAJELIS ALQURAN DI KEC.SALIMPAUNG KAB. TANAH DATAR SUMATERA BARAT
}

\author{
Hayati \\ IAIN Bukittinggi, hayatilillah@gmail.com \\ Nurhasnah \\ IAIN Bukittinggi,basnah_also@yahoo.com \\ Oktarina Yusra \\ IAINBukittinggi, riena_nabilab@yahoo.com
}

\begin{abstract}
Recitation of the Al-Qur'an located in Nagari Lawang Mandahiling, Kec. Salimpaung Kab. Tanah Datar West Sumatra is one of the branches of the Majelis Panjang Al-Qur'an Padang Panjang which is attended by the elderly who are usually known as the second group who are not much involved in intelligence activities such as memorizing the Qur'an. But in this study the researchers found that the elderly who participated in the study of the Al-Qur'an Council had been actively involved in the activities of studying the meaning of the verses of the Qur'an, memorizing and understanding it since 2014. This descriptive qualitative study aims to find out activities, secrets and factors underlying the ability of the elderly who are 60 years old and above in memorizing the Qur'an. Their activities are divided into six parts, namely the tahfidz preparation stage with motivation and tausiyah from the supervisor, then individual activities, daily activities, weekly activities, monthly activities and khataman activities for participants who have memorized one juz and are ready to perform the Qur'an memorization to the supervisor and pilgrims. The number of participants who have studied were six. Even though they have gone through the Khataman activities, this activity is not the end of the Tabfidz activity because they are still required to repeat their Qur'an memorization and increase their memory. The secret and the biggest factor that underlies the achievement of the Qur'anic verses in the elderly are internal factors in the form of the desire for old age to be filled with useful things and great rewards, love of the Qur'an, calm when interacting with the Qur'an and memorizing it, the desire to increase remembrance both in prayer or outside prayer, and faith and belief in the hereafter, in addition to other supporting external factors.
\end{abstract}

Keywords: Elderly, Memorizing the Qur'an, Salimpaung

\begin{abstract}
Abstrak
Pengajian Majelis Alquran yang berada di Nagari Lawang Mandabiling Kec. Salimpaung Kab. Tanah Datar Sumatera Barat merupakan salah satu cabang pengajian Majelis Alquran Padang Panjang yang diikuti oleh lansia yang biasanya dikenal sebagai kelompok kedua yang tidak banyak terlibat dalam aktivitas intelejensia seperti menghafal Alquran. Namun dalam penelitian ini peneliti menemukan bahwa lansia yang mengikuti pengajian Majelis Alquran ini sudah terlibat aktif dalam aktifitas mengkaji makna ayat Alquran, mentadaburi dan menghafalkannya semenjak tabun 2014 lalu. Penelitian yang bersifat deskriptif kualitatif ini bertujuan untuk menyingkap dan menyibak
\end{abstract}


aktifitas, rahasia serta faktor yang melatari kemampuan lansia yang rata-rata sudah berumur 60 tahun ke atas dalam menghafal Alquran. Aktifitas mereka dibagi menjadi enam bagian, yaitu tahap persiapan tabfidz. dengan adanya motifasi dan tausiyah dari pembimbing, kemudian kegiatan individu, kegiatan harian, kegiatan mingguan, kegiatan bulanan dan kegiatan khataman bagi peserta yang sudah hafal satu juz dan siap mentasmi'kan hafalannya kepada pembimbing dan jama'ah. Peserta yang telah khatam berjumlah enam orang. Meskipun sudah melalui kegiatan khataman, kegiatan ini bukan akhir dalam kegiatan tahfidz karena mereka masib dituntut untuk memuraja'ah dan menambah hafalan mereka. Rahasia dan faktor terbesar yang melatari ketercapaian tabfizd Alquran pada lansia tersebut adalah faktor internal dalam bentuk keinginan agar hari tua diisi dengan hal yang bermanfaat dan besar pahalanya, kecintaan terhadap Alquran, rasa tenang ketika berinteraksi dengan Alquran dan menghafalnya, keinginan meningkatkan qikir baik dalam sholat atau di luar sholat, dan keimanan serta keyakinan dengan hari akbirat, di samping ada faktor pendukung lain yang bersifat eksternal.

Kata Kunci: Lansia, Menghafal Alquran, Salimpaung

\section{PENDAHULUAN}

Allah menurunkan Alquran kepada manusia melalui risalah Nabi Muhammad SAW sebagai hidayah yang menjadi petunjuk dalam menjalani kehidupan di bumi dan pedoman dalam mengemban amanah khilafah. Agar fungsi Alquran termanifestasi dalam kehidupan seorang muslim, semestinya ada interaksi yang intensif dengan Alquran dalam rentang waktu yang konsisten. Adapun bentuk interaksi dengan Alquran menurut Alquran dan hadits adalah; 1. Interaksi tilawah ${ }^{1}$, yaitu membaca Alquran setiap hari dalam kuantitas tertentu, 2. Interaksi tadabbur ${ }^{2}$, yaitu penghayatan terhadap makna kandungan Alquran, 3. Interaksi menghafal Alquran, ${ }^{3}$ 4. Interaksi penerapan Alquran dalam kehidupan sehari-hari. ${ }^{4}$

Bentuk-bentuk interaksi ini telah mulai diterapkan oleh masyarakat Islam dunia pada umumnya. Khususnya di Indonesia, interaksi dengan Alquran secara resmi diwujudkan dalam aktivitas-aktivitas keagamaan di bawah kebijakan Kementerian Agama Republik Indonesia. Yaitu di

${ }^{1}$ Q.S Al-Baqarah : 121 Q.S Al-Muzammil : 4\&20, Q.S. an-Naml : $91-92$

${ }^{2}$ Q.S Muhammad : 24, Q.S Shad : 29.

${ }^{3}$ Q.S Al-Ankabut: 49

${ }^{4}$ Q.S Al-A'raf: 3, Az-Zumar: 18 \&55 antaranya MTQ Nasional $1^{5}$, Kurikulum Baca Tulis Alquran di $\mathrm{MDA}^{6}$ serta bantuan beasiswa bagi penghafal Alquran di lingkungan pendidikan.Adapun interaksi non resmi berupa aktivitas interaksi Alquran pada pengajian-pengajian non formal dan komunitas-komunitas Alquran.

Peserta aktivitas tahfizd Alquran di Sumatera Barat khususnya berasal dari berbagai kalangan dan umur mulai dari akademisi, professional, pedagang dan ibu rumah tangga.Mulai dari balita sampai lansia. ${ }^{7}$ Maraknya aktivitas tahfiz ini, merupakanbentuk komitmen seorang muslim terhadap pedoman hidup dan kebutuhan spiritual.

${ }^{5}$ Surat Keputusan Bersama (SKB) Menteri Agama dan Menteri Dalam Negeri No.182A tahun 1988 dan No.48 Tahun 1988 tentang Organisasi LembagaPengembangan Tilawatil Qur'an (LPTQ) dan Surat Keputusan Direktur Jenderal Pendidikan Tinggi No 3081/DIKTI/Kep/2014tanggal 16 Juli 2014 tentang Penetapan Universitas Indonesia sebagai PenyelenggaraMTQ Mahasiswa Tingkat Nasional XIV Tahun 2015.

6Peraturan Bersama Menteri Dalam Negeri dan Menteri Agama Nomor128 dan Nomor 4A Tahun 1982 Tentang Usaha Peningkatan Kemampuan Baca Tulis AlQur an Bagi Umat Islam dalam Rangka Penghayatan dan Pengamalan Al-Qur an dalamKehidupan Sehari-hari dan Instruksi Menteri Agama RI Nomor3 Tahun 1990 Tentang Pelaksanaan Upaya Peningkatan dan Kemampuan Baca Tulis Al-Qur ${ }^{\text {ee }}$ an

7 Dewi, MA, Wawancara langsung, pengurus Markaz al-Qur'an Sumatera Barat, 
Sebenarnya, Al-Quran itu adalah ayat-ayat yang nyata di dalam dada ${ }^{8}$ orang-orang yang diberi ilmu. dan tidak ada yang mengingkari ayat-ayat Kami kecuali orang-orang yang zalim.

Selain itu, yang menjadi motivasi banyak kalangan dalam menghafal Alquran adalah adanya pengaruh positif terhadap kesehatan fisik, kecerdasan IQ dan kestabilan emosional. Efek positif menghafal Alquran terhadap fisik, psikologi dan kecerdasan ini diuji dalam beberapa penelitian, di antaranya penelitian tentang pengaruh menghafal Alquran terhadap kecerdasan emosional santri Pondok Pesantren Alquran Muhammad Thaha alFasyni Bogor. Hasil penelitian ini menunjukkan adanya pengaruh yang signifikan pada kecerdasan emosional santri yang mengafal Alquran.' Adapun penelitian yang dilakukan di pondok pesantren tabfizul Qur'an Gembong pati Surabaya memberikan hasil adanya pengaruh yang baik terhadap kecerdasan spritual para penghafal Alquran. ${ }^{10}$

Selain pengaruhnya terhadap kecerdasan emosional dan kecerdasan spritual, menghafal Alquran juga memberikan pengaruh terhadap kecerdasan kognitif atau prestasi akademik. Hal ini dibuktikan dengan beberapa penelitian diantaranya penelitian yang dilakukan di Sekolah Agama Islam al-hidayah Bogor, penelitian tersebut memberikan kesimpulan bahwa adanya pengaruh positif dan signifikan menghafal Alquran mahasiswa yang menghafal Alquran terhadap prestasi akademik. ${ }^{11}$

${ }^{8}$ Maksudnya: ayat-ayat Al Quran itu terpelihara dalam dada dengan dihapal oleh banyak kaum muslimin turun temurun dan dipahami oleh mereka, sehingga tidak ada seorangpun yang dapat mengubahnya.

9 Melita Ayu Neni, pengaruh menghafal al-Qur'an terhadap kecerdasan emosional santri Pondok Pesantren Al-Qur'an Mubammad Thaha al-Fasyni Bogor, penelitian tidak dipublikasikan.

10 Dina Fitriani, Pengaruh Aktivitas Menghafal Alqur'an Terhadap Kecerdasan Piritual Santri Dipondok Pesantren AnakAnak Tabfidzul Qur'an (Ppatq) Raudlatulfalabbermi Gembong Patitahun 2016, Skripsi tidak dipublikasikan, UIN Semarang, 2016

11 M. Hidayat Ginanjar, Aktivitas Menghafal Al-Qur'an Dan Pengarubnya Terhadap Prestasi Akademik Mahasiswa (Studi Kasus Pada Mahasiswa Program Beasiswa Di Ma’had Huda Islami,
Motivasi-motivasi tersebut memberikan efek kepada minat menghafal Alquran karena aktivitas tahfidz Alquran merupakan aktivitas intelejensia yang mengandalkan kekuatan ingatan dan konsistensi kemauan melakukan pengulangan (muraj'ah).Maka, peminat tahfizd kebanyakan adalah peminat umur produktif. Namun, di antara aktivitas tahfiz Alquran yang marak di Sumatera Barat, ada sebuah lembaga tahfizd Alquran yang tergolong unik karena peserta penghafal Alqurannya adalah lansia. Aktivitas lansia tersebut yaitu pengajian Majlis Alquran Sumatera Barat yang dibimbing oleh ustadz H. Radison AR S.Ag. Pengajian ini dilaksanakan di beberapa kecamatan, kabupaten dan kota di Sumatera Barat, sebagian besar pesertanya adalah lansia. Menurut pembimbing pengajian tersebut, para lansia termotivasi menghafal Alquran dan ada yang telah hafal 8 juz ${ }^{12}$.

Sedangkan lansia yang dikenal sebagai kelompok kelas dua di lingkungan masyarakat yang berumur 60 tahun ke atas biasanya tidak banyak terlibat dalam aktivitas intelejensia seperti menghafal Alquran. Secara alamiah minat lansia lebih banyak kepada aktivitas sederhana dan ringan sesuai dengan hobi dan kebiasaan di masa muda, seperti rekreasi berupa meonoton TV, membaca koran berkunjung, piknik, menyulam, berkebun di sekitar rumah dan andil dalam organisasi masyarakat dan keagamaan. ${ }^{13}$

Berbeda dengan kecendrungan minat lansia di Nagari Lawang mandahiling salah satu cabang pengajian Majlis Alquran Padang Panjang.Beradasarkan observasi peneliti di Kecamatan Salimpaung pada hari Rabu tanggal 11 Mei 2017, aktivitas penghafalan Alquran mengawali

Tamansari Bogor), Jurnal Edukasi islam jurnal Pendidikan Islam Vol.06 No. 11 Januari 2017.

${ }^{12}$ H.Radison, AR, S.Ag (pembimbing Pengajian Majlis al-Qur'an Sumatera Barat), wawancara Langsung, tqnggal 11 Mei 2018

${ }^{13}$ Elizabeth B. Hurlock, Psikologi Perkembangan, edisi kelima, (Jakarta:Erlangga, 1980),hal. 387 
pengajian tematik intisari Alquran dan hadits. Satu jam sebelum pembimbing pengajian yaitu ustadz $\mathrm{H}$. Radison, AR, S.Ag datang, para peserta sibuk mengulang-ulang hafalan yang akan disetorkan kepada pembimbing. Sebelum Pembimbing pengajian menyampaikan tausiyah intisari Alquran dan hadits, beliau meminta peserta pengajian membacakan tambahan hafalannya satu per satu. Para peserta tampak antusias dan bersemangat menyetorkan hafalannya, meskipun masih terdapat kesalahan pengucapan fonologi huruf hijaiyah. Dalam proses penyimakan, pembimbing tidak langsung membetulkan kesalahan fonologi maupun tajwid karena khawatir mengganggu konsentrasi peserta dan melemahkan semangat peserta untuk terus menghafal ${ }^{14}$

Aktivitas ini tergolong unik karena secara teori psikologi perkembangan usia lanjut, pada umumnya lansia mengalami perubahan fisiologis, motoric dan mental. Perubahan ini menyebabkan keterbatasan bagi lansia dalam proses belajar, mengingat dan melafalkan kata. ${ }^{15}$ Khususnya dalam hal menghafal, secara alamiah pada usia tua, sejumlah neuron, unit-unit sel dasar dari system saraf menghilang. ${ }^{16}$ Fungsi neuron dicerebral cortex ini adalah menangani sebagian besar tugas kognitif. Penyebabnya lebih dominan kepada penciutan ukuran neuron tercepat pada frontal cortex, yang merupakan bagian penting bagi ingatan dan fungsi kognitif tingkat tinggi. ${ }^{17}$ Kondisi perubahan ini telah dijelaskan dalam Alquran surat al-Hajj ayat 5:

"Hai manusia, jikea kamu dalam keraguan tentang kebangkitan (dari kubur), Maka (ketabuilab) Sesunggubnya Kami telab menjadikan kamu dari tanah, kemudian dari

${ }^{14} \mathrm{H}$. Radison, AR. Wawancara Langsung, tanggal 12 Mei 2018

${ }^{15}$ Elizabeth B. Hurlock, Op.cit,hal. 388-394,

16 Desmita, Psikologi Perkembangan, (Bandung: PT. Remaja Rosdakarya, 2008), h. 237.

17 Diane E. Papalia, Sally Wendkos Old dan Ruth Duskin Feldmen, Psikologi Perkembangan, Bag. $V$ s/d IX, (Jakarta: Kencana Prenada Media Group, 2011), h. 858 setetes mani, kemudian dari segumpal darah, kemudian dari segumpal daging yang sempurna kejadiannya dan yang tidak sempurna, agar Kami jelaskan kepada kamu dan Kami tetapkan dalam rahim, apa yang Kami kehendaki sampai waktu yang sudah ditentukan, kemudian Kami keluarkan kamu sebagai bayi, kemudian (dengan berangsur- angsur) kamu sampailah kepada kedewasaan, dan di antara kamu ada yang diwafatkan dan (adapula) di antara kamu yang dipanjangkan umurnya sampai pikun, supaya Dia tidak mengetabui lagi sesuatupun yang dabulunya telah diketahuinya. dan kamu Libat bumi ini kering, kemudian apabila telah Kami turunkan air di atasnya, biduplah bumi itu dan suburlah dan menumbubkan berbagai macam tumbubtumbuhan yang indah."

Namun pada pengajian ini kondisi tersebut seakan tidak berlaku. Berdasarkan wawancara peneliti dengan salah seorang peserta pengajian yang bernama Saiyar berumur 70 tahun, beliau rutin mengikuti pengajian dan bersemangat menghafal Alquran serta menyetorkannya di pengajian. Saiyar tidak merasa ada kendala dan kesulitan yang berarti dalam menghafal Alquran, bahkan semakin bersemangat dan yakin bisa terus bertambah hafalannya hari demi hari. Semangat itu dilatarbelakangi oleh kebutuhan ruhani dan kebutuhan hiburan. Kebutuhan ruhani terpenuhi oleh materi pengajian dan aktivitas bersama Alquran. Sedangkan kebutuhan hiburan terpenuhi oleh wisata ruhani ke daerah tertentu dan berkumpul untuk muraja'ah bersama peserta pengajian lain dari berbagai daerah di Sumatera Barat. Wisata ruhani ini rutin dilaksanakan sekali dalam satu bulan. ${ }^{18}$

Adapun majlis Alquran Sumatera Barat ini merupakan pengajian lansia yang bermetamorfosis dari tradisi lama kepada pengajian opensif yang terbuka menerima perkembangan di luar pengajian. Baik perkembangan materi dan metode pengajian selagi masih berdasarkan Alquran dan Hadits.

\footnotetext{
${ }^{18}$ Saiyar, wawancara langsung, 4 Mei 2017.
} 
Materi yang disampaikan dalam pengajian tersebut sangat fleksibel dan kontekstual. Di samping memberikan layanan keagamaan berupa ilmu agama dan menghafal Alquran juga memberikan layanan hiburan dan kebahagiaan dengan kegiatan wisata ruhani. Namun secara aplikatif pengajian ini belum terpublikasi secara ilmiah dan belum mendapatkan dukungan yang cukup dari pemerintah, khususnya dukungan materil. Dukungan materil dibutuhkan untuk transportasi wisata ruhani ${ }^{19}$. Sedangkan dukungan edukasi berupa keterlibatan akademisi bahasa Alquran dalam proses aktivitas tahfizd Alquran sebagai peneliti ketepatan proses tahfizd Alquran, karena secara formal lansia di Kec. Salimpaungberpendidikan rendah. ${ }^{20}$ Melalui penelitian ini, sebagai bagian dari masyarakat peneliti ingin berkontribusi secara ilmiah dengan melakukan penelitian terhadap aktivitas tahfidz Alquran bagi lansia di pengajian Majlis Alquran khususnya di Kecamatan Salimpaung Kabupaten Tanah Datar.

\section{PELAKSANAAN KEGIATAN TAHFIZ LANSIA DI PENGAJIAN SURAU BARU JORONG LAWANG MANDAHILING}

Pengajian Alquran yang dilaksanakan di mesjid Taqwa Lawang telah dimulai sejak lebih dari 30 tahun lalu. Pengajian ini merupakan aktivitas rutinitas keagamaan masyarakat nagari Lawang Mandahiling yang dilaksanakan setiap hari selain hari Jum'at.

Menurut pembimbing pengajian, pada awalnya pengajian hanya membaca Alquran dan terjemahan per kata dan mengkaji beberapa kitab kuning dengan tema tafsir, tarikh, Fiqih, Akidah dan Akhlak. Kitab-kitab tersebut dibahas berulang selama bertahun-tahun. Kemudian, 4 tahun lalu tepatnya pada tahun 2014 barulah pengajian ini

\footnotetext{
${ }^{19}$ Ruwaida, wawancara Langsung, 4 Mei 2017.

${ }^{20}$ Mesra Yulida (Anggota BPRN Kec. Salimpaung), wawancara Langsung, tanggal 12 Mei 2018.
}

menerapkan model talaqi dan tasmi'. Proses pelaksanaan kegiatan tahfidz lansia ini dilaksanakan dengan beberapa tahap

Persiapan Tabfiz.

Aktivitas tahfiz ini dimulai pada tahun 2014 dengan inspirasi bapak Radison AR S.Ag seorang pembina tahfiz lansia di beberapa daerah di Sumatera Barat. Kegiatan diawali dengan motivasi dan tausiyah tentang pentingnya menghafal Alquran dan meningkatkan interaksi dengan Alquran. Kemudian dilanjutkan dengan pembacaan ayat-ayat yang akan dihafal yaitu dimulai dari juz 1 surat alBaqarah. Pada persiapan ini, pembimbing membacakan beberapa ayat kemudian diikuti oleh peserta tahfiz.

Pada persiapan ini pembimbing membaca dengan perlahan-lahan secara tartil beberapa kali.Kemudian diikuti oleh peserta pengajian.Kegiatan persiapan ini dilaksanakan selama 30 menit. Setelah itu, pembimbing memberikan motivasi kembali kepada peserta untuk menghafal di rumah dan disetor minggu berikutnya.

Kegiatan tahfidz diikuti oleh semua peserta lansia yang aktif berjumlah 25 orang berikut:

\begin{tabular}{|l|l|l|l|}
\hline No & Nama & Umur & Pekerjaan \\
\hline $\mathbf{1}$ & Samsulinar & 75 tahun & Tani \\
\hline $\mathbf{2}$ & Asdiwarti & 66 tahun & Tani \\
\hline $\mathbf{3}$ & Asniarti & 63 tahun & Tani \\
\hline $\mathbf{4}$ & Hartati & 53 tahun & Tani \\
\hline $\mathbf{5}$ & Martiny & 73 tahun & Tani \\
\hline $\mathbf{6}$ & Darnis & 74 tahun & Tani \\
\hline $\mathbf{7}$ & Mainis & 70 tahun & Tani \\
\hline $\mathbf{8}$ & Asminarti & 75 tahun & Tani \\
\hline $\mathbf{9}$ & Erni & 54 tahun & Tani \\
\hline $\mathbf{1 0}$ & Raunas & 80 tahun & Tani \\
\hline $\mathbf{1 1}$ & Zulpa & 65 tahun & Tani \\
\hline $\mathbf{1 2}$ & Syamsidar & 83 tahun & Tani \\
\hline $\mathbf{1 3}$ & Nurma & 86 tahun & Tani \\
\hline $\mathbf{1 4}$ & Hermida & 63 tahun & Tani \\
\hline $\mathbf{1 5}$ & Syamsinas & 55 tahun & Tani \\
\hline
\end{tabular}




\begin{tabular}{|c|c|c|c|}
\hline 16 & Puspita Astuti & 55 tahun & Tani \\
\hline 17 & Murni Lathif & 75 tahun & Tani \\
\hline 18 & Yen & 47 tahun & Tani \\
\hline 19 & Peri & 50 tahun & Tani \\
\hline 20 & Saiyar & 73 tahun & Tani \\
\hline 21 & Raidanis & 69 tahun & Tani \\
\hline 22 & Aninen & 78 tahun & Tani \\
\hline 23 & Mesra yulida & 48 tahun & Guru \\
\hline 24 & Irdawati & 55 tahun & Tani \\
\hline 25 & Yusneti & 60 tahun & Tani \\
\hline
\end{tabular}

\section{$\underline{\text { Kegiatan individu }}$}

Kegiatan individu dilakukan oleh masingmasing peserta di rumah mereka di sela-sela kesibukan harian sebagai petani. Peserta tahfiz lansia melakukan kegiatan individu pada waktu dan metode yang berbeda. Pemilihan waktu yang lebih utama bagi peserta adalah setelah shalat tahajjud.

Adapun metode menghafal yang diterapkan oleh peserta tahfiz lebih dominan dengan visual dengan menggunakan metode tikrar yaitu dengan membaca ayat pada mushaf berulang-ulang.

Ayat-ayat yang telah dihafal kemudian dimuraja'ah atau diualng setiap hari oleh peserta secara individu.Beberapa kendalan yang dihadapi oleh peserta tahfiz adalah kendala kekuatan memori hafalan, hafalan dihafal pagi akan mudah hilang di sore harinya.

\section{$\underline{\text { Kegiatan Harian }}$}

Kegiatan harian tahfidz peserta pengajian Surau Baru Jorong Lawang Mandahiliang dilaksanakan 5 hari dalam seminggu yaitu setiap hari senin sampai kamis dan hari sabtu. Hari Jumat pengajian diliburkan karena hari pakan, di mana pada hari tersebut peserta pengajian ke pasar mingguan guna membeli stok pangan untuk seminggu. Hari ahad juga diliburkan karena masjid tempat pelaksanaan kegiatan pengajian digunakan oleh murid-murid TPA untuk kegiatan didikan subuh.

Berdasarkan observasi peneliti tanggal Setiap hari aktif pengajian, peserta mengulangi hafalan yang dihafal secara berjamaah selama 10 menit, kemudian pembimbing pengajian meminta salah seorang peserta mentasmi'kan hafalannya. Pembimbing dan peserta yang lain menyimak hafalan peserta sembari memperbaiki kesalahan. Setelah proses pengulangan hafalan bersama dan tasmi' peserta, kegiatan pengajian dilanjutkan dengan penterjemahan Alquran per kata. Kemudian dilanjutkan dengan pembahasan tafsir. Kegiatan ini dipandu oleh pembimbing pengajian. Selanjutnya pengajian tafsir dilanjutkan dengan pengajian kitab klasik.

\section{$\underline{\text { Kegiatan Mingguan }}$}

Kegiatan mingguan ini dilaksanakan setiap hari Rabu dengan bimbingan Bapak H. Radison AR. Penggiat kegiatan Alquran di beberapa daerah di Sumatera Barat. Pada kegiatan mingguan ini, pembimbing memandu peserta pengajian mengulang hafalan bersama secara berjamaah. Muraja'ah hafalan ini dilaksanakan selama 15 menit. Kemudian dilanjutkan dengan tasmi' perorangan yang ditunjuk langsung oleh pembimbing. Tasmi' perorangan ini diprioritaskan kepada peserta yang memiliki hafalan akselerasi. Peserta akselerasi ini adalah peserta yang memiliki hafalan di atas standar hafalan bersama. Peserta akselerasi ini berjumlah 7 orang lansia.

Pada pelaksanaan muraja'ah, pembimbing tidak langsung memperbaiki kesalahan bacaan, baik dalam muraja'ah bersama maupun tasmi' perorangan kecuali kesalahan yang fatal seperti salah sambung ayat. Pembimbing memperbaiki bacaan setelah pelaksanaan muraja'ah secara kolektif. Alasan pembimbing tidak langsung memperbaiki adalah untuk menghindari kehilangan konsentrasi dan kebuyaran hafalan peserta dikarenakan peserta sudah lanjut usia. 
Setelah proses muraja'ah dan tasmi', pembimbing melanjutkan dengan kajian tafsir tematik. Pada kajian tematik, pembimbing meningkatkan interaksi peserta terhadap Alquran dengan tadabbur ayat dan berusaha mengamalkan Alquran dalam kehidupan sehari-hari. Kepiawaian pembimbing mengkaji tafsir tematik ini yang menjadi alasan peserta termotivasi untuk konsisten mengikuti pengajian Alquran mingguan ini.

\section{Kegiatan Bulanan}

Kegiatan bulanan tersebut dilaksanakan di Padang Panjang pada pengajian yang dikelola oleh H.Radison, AR atau digilir di masjid pada daerah yang mengusulkan tempat kajian gabungan. Kegiatan bulanan ini melibatkan peserta tahfidz lansia yang berasal dari berbagai daerah di Sumatera Barat. Kegiatan bulanan ini selain sebagai kegiatan pengajian dan kegiatan muraja'ah gabungan, juga dijadikan wadah silaturrahim, refreshing bagi peserta yang sudah lanjut usia.

Pelaksanaan kegiatan tahfidz gabungan ini berupa muraja'ah bersama.Peserta yang hadir lebih kurang 100 orang lansia dari berbagai daerah di Sumatera Barat. Setelah pelaksanaan muraja'ah berjamaah, dilanjutkan dengan kajian tafsir tematik. Kegiatan ini memberikan kesan yang positif untuk peserta tahfidz lansia dalam meningkatkan motivasi menghafal.

Pada kegiatan bulanan ini, seluruh peserta tidak bisa rutin mengikutinya. Kegiatan ini hanya diikuti oleh peserta yang memiliki biaya dan akomodasi untuk berangkat ke daerah lain.

\section{Kegiatan Khataman}

Sebagai kegiatan puncak dalam aktivitas pengajian Surau Baru adalah kegiatan khataman. Kegiatan khataman ini dilaksanakan apabila peserta telah menyelesaikan hafalan satu juz dan sudah yakin siap mentasmi'kan hafalannya kepada pembimbing dan jama'ah. Pelaksanaan kegiatan khataman dilaksanakan di kediaman peserta yang bersangkutan dan dihadiri oleh peserta pengajian dan keluarga besar peserta khatam dan tetangga dekat. Kegiatan ini dirancang seperti syukuran agar menjadi syiar dan motivasi bagi yang lain.

Prosedur kegiatan khataman ini dimulai dengan setoran harian, mingguan dan bulanan yang sudah dilaksanakan. Setelah peserta menyelesaikan hafalan per 1 juz dan sudah mutqin, diajukan kesiapannya kepada pembimbing untuk dijadwalkan waktu khatamannya.

Kegiatan ini dimulai dengan pengantar dari pembimbing tentang profil peserta hafalan, kemudian dilanjutkan dengan tasmi' hafalan sebanyak satu juz sekaligus di kursi khusus dan berlatar banner profil peserta khataman. Tasmi' dibacakan di hadapan ustadz Radison AR sebagai pembimbing utama dan para tamu undangan yang terdiri dari peserta Pengajian Surau Baru, keluarga besar dan tetangga serta tamu lainnya. Pembimbing tidak secara spontan memperbaiki kualitas hafalan yang berkaitan dengan ketepatan tajwid dan kelancaran hafalan. Alasan pembimbing tidak melakukan perbaikan agar tidak mengganggu konsentrasi peserta khataman dalam mentasmi'kan hafalannya. Setelah pelaksanaan setoran hafalan 1 juz, pembimbing memberi motivasi kepada peserta khataman untuk terus memuraja'ah hafalan yang telah diujikan dan melanjutkan hafalan juz berikutnya. Sebagai penutup, pembimbing memimpin doa bersama dan dilanjutkan dengan makan bersama yang disedekahkan oleh keluarga peserta khataman.

PROGRAM TINDAK LANJUT AKTIVITAS TAHFIDZ LANSIA PENGAJIAN SURAU BARU JORONG LAWANG MANDAHILIANG

Kegiatan khataman bukan tujuan akhir dan bukan aktivitas terakhir. Pada akhir prosesi khataman, pembimbing utama memberi pesan dan tausiyah agar peserta terus memuraja'ah hafalan dan menjadikan hafalan tersebut sebagai modal 
memperbaiki kualitas ibadah shalat dan menjadi koleksi zikrullah yang dilantunkan oleh penghafal setiap harinya.

Guna menjaga hafalan yang telah disetorkan pada prosesi khataman, diterapkan sistem muraja'ah berkala pada kegiatan harian, mingguan dan bulananan. Pada kegiatan-kegiatan tersebut, peserta yang telah khatam diprioritaskan mentasmi'kan hafalannya yang dalam bentuk muraja'ah atau setor hafalan baru. System ini dipandang efektif karena peserta yang telah mengikuti prosesi khataman juz 1 terus melanjutkan ke juz 2.

\section{KUALITAS TAHFIZ LANSIA DI PENGAJIAN SURAU BARU JORONG LAWANG MANDAHILING}

Setelah dilakukan penelitian, dapat disimpulkan bahwa kualitas tahfidz lansia ini tergolong baik. Hal dapat dilihat pada beberapa segi.

\section{Dari Segi Pelafadzan Huruf Hijaiyyah}

Secara garis besar, pelafadzan hurufhijaiyyah berdasarkan makharij al-buruf dan shifat alburuf pada peserta pengajian sudah baik. Namun ada beberapa huruf yang kurang tepat pelafadzannya, seperti pelafadzan huruf ش yang dibaca w pada kata فراشا, kurang tepat pada pelafadzan huruf s yang seharusnya memiliki shifatal-hams pada kata من قبلك.

\section{Dari Segi Hukum Tajwid}

Secara garis besar, kesalahan hukum tajwid yang ditemukan pada peserta pengajian hanyalah kesalahan khafiy, yaitu yang menyalahi 'urf qurro', namun tidak sampai merubah arti, seperti tidak membaca ghunnah, kurang panjang dalam membaca mad wajib muttashil, dan lain-lain seperti kurang dengung pada ikhfa' haqiqi pada kata إن كنتم, kurang panjang pada mad wajib muttashil yang bisa السفهاء dibaca 4-6 harakat pada kata

\section{Dari Segi Kelancaran}

Secara umum, peserta pengajian sudah berusaha agar hafalannya tepat dan lancar. Kualitas hafalan peserta yang khataman sangat baik, rata-rata menyetorkan hafalan dalam waktu 50 menit. Namun di beberapa ayat masih ditemukan kekuranglancaran. Jika ada peserta yang kurang lancar, maka akan dibantu oleh Bapak Radison selaku inspirator dan pembimbing pengajian tersebut.

\section{Dari Segi Penghayatan}

Adapun dari segi penghayatan terhadap ayat yang dibaca, ada diantara peserta yang menangis ketika membaca ayat tentang azab. Hal ini disebabkan karena mereka telah membahas arti tiap kata pada ayat yang akan mereka hafal sebelum mereka mulai menghafal.

\section{FAKTOR KETERCAPAIAN TAHFIDZ LANSIA DI PENGAJIAN SURAU BARU JORONG LAWANG MANDAHILIANG}

Adapun faktor keberhasilan peserta pengajian yang telah mengikuti kegiatan khataman terbagi kepada 2 macam.

Faktor Internal. Yaitu faktor motivasi yang lahir dalam dari diri peserta. Diantara motivasi tersebut adalah keinginan agar hari tua diisi dengan hal yang bermanfaat dan besar pahalanya, kecintaan terhadap Alquran, rasa tenang ketika berinteraksi dengan Alquran dan menghafalnya, keinginan meningkatkan zikir baik dalam sholat atau di luar sholat, dan keimanan serta keyakinan dengan hari akhirat.

Faktor eksternal. Yaitu intensitas mengikuti pengajian interaksi Alquran, tren tahfidz yang massif di tengah masyarakat, dan aktivitas rutin tadabbur ayat Alquran yang diikuti.

Faktor-faktor di atas adalah diantara faktor yang melatari keberhasilan lansia peserta pengajian dalam menghafal Alquran meskipun mereka menghadapi berbagai kendala selama menghafal. 


\section{KESIMPULAN}

Pelaksanaan kegiatan tahfidz yang diikuiti oleh lansia di kec. Salimpaung Kab. Tanah datar dibagi menjadi beberapa tahap, yaitu: tahap persiapan tahfidz, kegiatan individu, kegiatan harian, kegiatan mingguan, kegiatan bulanan, dan kegiatan khataman. Setelah khataman ini masih ada program tindak lanjut aktivitas tahfidz. Pada kegiatan tersebut, peserta yang telah khatam diprioritaskan mentasmi'kan hafalannya yang dalam bentuk muraja'ah atau setor hafalan baru. System ini dipandang efektif karena peserta yang telah mengikuti prosesi khataman juz 1 terus melanjutkan ke juz 2.

Kualitas tahfidz lansia ini sudah termasuk baik jika dilihat dari beberapa segi, diantaranya segi pelafadzan huruf hijaiyyah, segi hukum tajwid, segi kelancaran dan segi penghayatan. Kesalahan yang ditemukan pada pelafadzan huruf hijaiyyah seperti pelafadzan huruf ش menjadi w dll. Kesalahan dari segi hukum tajwid kebanyakannya hanyalah kesalahan yang bersifat khafiy yang tidak sampai merubah makna. Peserta mampu menyetorkan hafalan dalam waktu 50 menit, dan di beberapa ayat seperti ayat tentang adzab ada yang menangis.

Rahasia dan faktor terbesar yang melatari ketercapaian tahfidz lansia ini adalah faktor internal berupa motivasi dan keinginan yang lahir dari dalam diri peserta, dan didukung oleh faktor lain yang bersifat eksternal.

\section{DAFTAR KEPUSTAKAAN}

Ahmadi, Cholid Narbuko Abu, 1997. Metode Penelitian, Jakarta: PT. Bumi Aksara, Cet. Ke-1

Al-Hafizh, Majdi Ubaid, 2015.Langkah Mudah Menghafal Alquran, Solo: Aqwam, Cet. 2

al-Huwail, Ibrahim Sulaiman, Tth.Taqwim Ta'lim Hifz Alquran al-Karimwa ta'limih, Riyadh: Halaqah Jam'iyah Tahfiz Qur'an

al-Mazyd, Ahmad dan Adil asy-Syady, 2018.Cara Mudah Menghafal Alquran \& Menjaga Hafalan, Jakarta: Darul Haq
al-Qathan, Manna' Khalil.Mabahits Fi Ulum Alquran, Mansyurat al-'Ashri al-Hadits),

Desmita, 2008.Psikologi Perkembangan, Bandung: PT. Remaja Rosdakarya

Diane E. Papalia, Sally Wendkos Old dan Ruth Duskin Feldmen, 2011.Psikologi Perkembangan, Bag. $V$ s/d IX, Jakarta: Kencana Prenada Media Group

Faisal, Sanafiyah, 2004. MetodologiPenelitianPendidikan, Surabaya: Usaha Nasional

Fitriani, Dina, 2016.Pengaruh Aktivitas Menghafal Alqur'an Terbadap Kecerdasan Piritual Santri Dipondok Pesantren Anak-Anak Tabfidzul Qur'an (Ppatq) Raudlatulfalabbermi Gembong Patitabun 2016, Skripsi tidak dipublikasikan, UIN Semarang

Ginanjar, M. Hidayat, Aktivitas Menghafal Alquran Dan Pengarubnya Terbadap Prestasi Akademik Mahasiswa (Studi Kasus Pada Mahasiswa Program Beasiswa Di Ma'had Huda Islami, Tamansari Bogor), Jurnal Edukasi islam jurnal Pendidikan Islam Vol.06 No. 11 Januari 2017

Gunawan, Imam, 2015.Metode Penelitian Kualitatif Teori dan Praktek, Jakarta: PT. Bumi Aksara

Hannani, Silfia, 2006.Peranan Ulama Dalam Penyebaran agama Islam,Bangi: Dewan Bahasa dan Pustaka Kuala Lumpur

Hasan, Purwakania, 2006.Psikologi Perkembangan Islami, Jakarta: PT Raja Grafindo Persada

Hurlock, Elizabeth B., 1980.Psikologi Perkembangan, edisi kelima, Jakarta: Erlangga

Moleong, Lexy J., 1995. Metode Penelitian Kualitatif, Bandung: PT. Rineka Rosda Karya, cet. Ke5

Nashr, Athiyah Qabil, 1994.Ghayatul Murid Fi Ilm alTajwid, Kairo : Mazidah wa Manqahah

Nelmaya, Pelayanan Kegamaan Manula Oleb Ulama Tradisional Beraliran Tariqat Naqsyabandiyah di Lasi Kec. Candung Kabupaten Agam. Jurnal Analisis Vol. 12 No.1, Januari -Juli 2015 (Bukittinggi: LPM IAIN Bukittinggi)

Neni, Melita Ayu, pengarub menghafal Alquran terbadap kecerdasan emosional santri Pondok Pesantren Alquran Muhammad Thaha al-Fasyni Bogor, penelitian tidak dipublikasikan. 
Rauf, Abdul Aziz Abdul, Pedoman Daurah Alquran Kajian Ilmu Tajwid, (Jakarta Timur: Lembaga Pengembangan Potensi Keilmuan Islam Markaz Alquran, 2007), Cet-11

Sutarip, Sobari, 2010.Menghafal Alquran Dengan Cepat \& Mudah, Iqra Kreativ, Cet. 2

Tohirin, 2008.Psikologi Pembelajaran Pendidikan Agama Islam, Jakarta: PT.Raja Grafindo Persada

Yusuf, M. Kadar. 2014. Studi Alquran, Jakarta: Amzah, Cet-2

\section{Wawancara dan Sumber Lainnya}

Dewi, MA, Wawancara langsung, pengurus Markaz Alquran Sumatera Barat.

H.Radison, AR, S.Ag (pembimbing Pengajian Majlis Alquran Sumatera Barat), wawancara Langsung, tanggal 11 Mei 2018

H. Radison, AR. Wawancara Langsung, tanggal 12 Mei 2018

Mesra Yulida (Anggota PPRN Kec. Salimpaung), wawancara Langsung, tanggal 12 Mei 2016.

Puspita Astuti, Pendamping Pengajian majlis Alquran Lawang, wawancara langsung, $30 \mathrm{Juli}$ 2018

Puspita Astuti, wawancara langsung, 11 Agustus 2018

Raidanis, Bendahara Pengajian Majlis Alquran Lawang, wawancara langsung, 23 Juli 2018

Ruwaida, wawancara Langsung, 4 Mei 2018.

Saiyar, Anggota Pengajian, wawancara langsung, 8 Agustus 2018

Saiyar, wawancara langsung, 4 Mei 2018.

Samsulinar, Pembimbing Pengajian Majlis Alquran Lawang, wawancara langsung, 30 Juli 2018

Samsulinar, Raidanis, Saiyar, Mesra Yulida, wawancara langsung, 11 Agustus 2018

Surat Keputusan Bersama (SKB) Menteri Agama dan Menteri Dalam Negeri No.182A tahun 1988 dan No.48 Tahun 1988 tentang Organisasi Lembaga Pengembangan Tilawatil Qur'an (LPTQ) dan Surat Keputusan Direktur Jenderal Pendidikan Tinggi No 3081/DIKTI/Kep/2014tanggal 16 Juli 2014 tentang Penetapan Universitas Indonesia sebagai PenyelenggaraMTQ Mahasiswa Tingkat Nasional XIV Tahun 2015.
Peraturan Bersama Menteri Dalam Negeri dan Menteri Agama Nomor128 dan Nomor 4A Tahun 1982 Tentang Usaha Peningkatan Kemampuan Baca Tulis Al-Qur'an Bagi Umat Islam dalam Rangka Penghayatan dan Pengamalan Al-Qur an dalamKehidupan Sehari-hari dan Instruksi Menteri Agama RI Nomor3 Tahun 1990 Tentang Pelaksanaan Upaya Peningkatan dan Kemampuan Baca Tulis Al-Qur'an 